\title{
Assessment of the Anabolic Effect of Androgens of the Edible Portion of the Shoot of Giginya Plant (Borassus aethiopum mart)
}

\author{
J. A. Akinniyi ${ }^{1}$, M. Waziri ${ }^{2}$, and H. S. Usman ${ }^{3}$ \\ ${ }^{1}$ Department of Chemistry, University of Maiduguri, Nigeria \\ ${ }^{2}$ Department of Chemistry, BAI University, Damaturu, Nigeria \\ ${ }^{3}$ Department of Veterinary Pathology, University of Maiduguri, Nigeria \\ Received 22 January 2010, accepted in final revised form 25 March 2010
}

\begin{abstract}
The young shoot of the germinating fruit of Borassus aethiopum mart locally called Muruchi was evaluated for anabolic effects using spectrophotometric techniques and administration of the Muruchi extract to experimental animals. The growth rate, blood amino acid nitrogen and blood urea nitrogen levels were monitored twenty four hourly during the growth trial period of twenty eight days conducted on growing rabbits (lapine species). Results of the study revealed strong comparison of the extract with a standard anabolic androgen (fluoxymesterone), indicating the anabolic effects of androgens of Muruchi.
\end{abstract}

Keywords: Borassus aethiopum; Growth trial; Lapine species; Fluoxymesterone.

(C) 2010 JSR Publications. ISSN: 2070-0237 (Print); 2070-0245 (Online). All rights reserved.

DOI: $10.3329 /$ jsr.v2i2.4173

J. Sci. Res. 2 (2), 362-368 (2010)

\section{Introduction}

The anabolic effect or growth stimulation of the androgens (male sex hormones) is a manifestation of their metabolic action, which consists principally of protein synthesis and decrease in protein breakdown. The effects of which are reflected in increase in body weight due to an increase in skeletal muscle and development of growth spurt with increase in bone matrix and skeletal length in growing organisms [1, 2]. There are also specific stimulation of growth of the prostate and seminal vesicles, in addition to the selective increase in size and weight of the kidneys (renotropic action). The relationship of such effects and changes in the activities of certain renal enzymes such as D-amino acid oxidase to metabolic action of androgens is not clear. The diminished excretion of certain minerals such as urea and increased storage of protein have all been associated with the metabolic action of androgens [3].

\footnotetext{
${ }^{2}$ Corresponding author: maimunakadai@yahoo.com
} 
Blood levels of amino acids and urea may also be considered to partly reflect the metabolic action of androgen as may be noted from the dynamic equilibrium which exists between the various body proteins [4]. The existence of an 'amino acid pool' which is contributed continually by degradation of these proteins is continually drawn upon for resynthesis. Accordingly, the concentration of free amino acids in the plasma, representing the extracellular fluids is the resultant of these anabolic and catabolic processes. In the absence of protein intake which temporarily increases the blood amino acid level, severe liver damage also increases blood amino acid levels due to decreased deamination with corresponding decrease in urea. However, the administration of insulin and androgens are known to bring about a fall in plasma amino acid levels. Thus, in the absence of the factors enumerated, the plasma amino acid level may be employed to measure the anabolic action of androgens. Urea, on the other hand is the major nitrogenous end product of protein metabolism, representing the amino groups ingested or produced in the body in excess of the requirement or capacity for synthesis of body proteins and other nitrogenous compounds [5-7]. Blood urea may rise temporarily to the upper limits of normal following a meal rich in protein while low values are obtained during periods of dietary protein restriction and also during pregnancy due to increase in nitrogen requirements for reproduction. However, concentration of blood urea will also fall following administration of growth hormone and androgens due to stimulation of protein synthesis. Therefore, as in the case of amino acid level, urea level may also be used to measure the anabolic effect of androgens provided all the other mentioned factors are controlled. The parameters to be used in measuring the anabolic action of androgens in this study include change in body, plasma amino acid level and plasma urea level.

The Plant: Borassus aethiopum mart has been described as a palm tree with huge fan shaped leaves. The various ethnic groups in Nigeria identify this plant by different names. The Hausa call it Giginya, the Yoruba call it Agbon Oludu, the Ibos call it Ubiri and the Kanuri's know it as Kemelutu.

The young germinating shoot of the plant is called Muruchi in Hausa. Muruchi is only well known in northern Nigeria and it is seasonally in the local markets. The people both young and old consume Muruchi either raw or boiled as food and they claim that it enhances libido in women and has aphrodisiac properties in men.

The objective of this study is to determine the anabolic effect of androgens in the acetone extract of Muruchi by comparing it with a strongly anabolic steroidal hormone, fluoxymesterone to ascertain whether or not our findings can be associated with the claim of the consumers.

\section{Materials and Methods}

\subsection{Collection of samples}

About $4 \mathrm{~kg}$ of Muruchi was collected from Shani local government area of Borno State Nigeria in the month of December. Both fresh and air dried samples of the material were used in the study. 


\subsection{Preparation of extract}

Two hundred grams (200g) of Muruchi was extracted with acetone over a soxhlet extractor over a period of eight to twelve hours and filtered. The extract was recovered by evaporation of solvent over a rotary evaporator below the boiling point of acetone. Further trapped solvents were removed from the extract using freeze drier. The extract yield was $20 \%$ and was used without further purification.

\subsection{Preparation of standard solution}

One capsule of the androgen, equivalent to $25 \mathrm{mg}$ of the hormone (flouxymesterone), was dissolved in $100 \mathrm{~cm}^{3}$ of distilled water and used as standard. This contained approximately $250 \mu \mathrm{g} / \mathrm{cm}^{3}$ of the hormone [8].

\subsection{Preparation of extract solution}

One gram (1g) of the extract was dissolved in $100 \mathrm{~cm}^{3}$ of distilled water and kept in a refrigerator as stock solution of Muruchi extract. Comparison with flouxymesterone standard showed that extract solution contained $2200 \mu \mathrm{g} / \mathrm{cm}^{3}$ androgen [9].

\subsection{Plan of the experiment}

Growing male rabbits weighing $0.8 \mathrm{~kg}$ to $1.0 \mathrm{~kg}$ were used for this study. A total of 24 experimental animals were involved and four days were allowed for the animals to adapt to the controlled diet and experimental conditions. The animals were then serially numbered, categorized into three groups (A, B, C) of eight and each group housed separately in cages. Each animal was weighed, and were mixed together in such a way that the average weight of the groups $\mathrm{A}, \mathrm{B}, \mathrm{C}$ were the same. The set of groups $\mathrm{A}$ and $\mathrm{C}$ were used as controls. Group A received flouxymesterone and group B received Muruchi extract while the control group $\mathrm{C}$ were given distilled water.

\subsection{Administration of drug/extract}

The required daily dose of $0.62 \mathrm{mg}$ [10] of the extract and drug were administered intragastrically to the experimental animals for 28 days.

\subsection{Determination of blood amino acid nitrogen and blood urea nitrogen}

The protein-free blood filtrate was used to determine the blood amino nitrogen and blood urea nitrogen using standard analytical techniques.

\subsection{Growth trial}

Growth trial study was conducted to measure changes in body weight as a result of particular feeding regime. Animals were fed with groundnut tops (Arachis hypogaea) 
locally called Harawa and water in addition to the administered drug and extract. Composition of the Harawa is shown in appendix I. The changes in body weight were compared to those of animals on standard diet and those on controlled diet. The diets were administered over a given period and changes in body weight of experimental animals were noted.

\subsection{Data analysis}

The statistical analysis were carried out using Microsoft excel and Analysed-it software [11]. Results obtained were expressed as mean \pm SEM (standard error of mean) and student's t-test was used at a level of significance of $p<0.05$.

\section{Results and Discussion}

The data on growth trial are presented in Figs. 1, 2 and 3. Both extract and hormone exhibited a significant $(p<0.05)$ increase in weight. In Fig. 1, it may be observed that during the first two weeks, both the hormone and the Muruchi extract increased growth rate, though this anabolic effect was more pronounced for the hormone. Similarly between the second and third weeks, both the hormone and the extract showed increase in growth. By the end of the fourth week, the hormone showed a slight increase in growth to an approximately the same extent as the Muruchi extract. However, such trend was not observed in the control group.

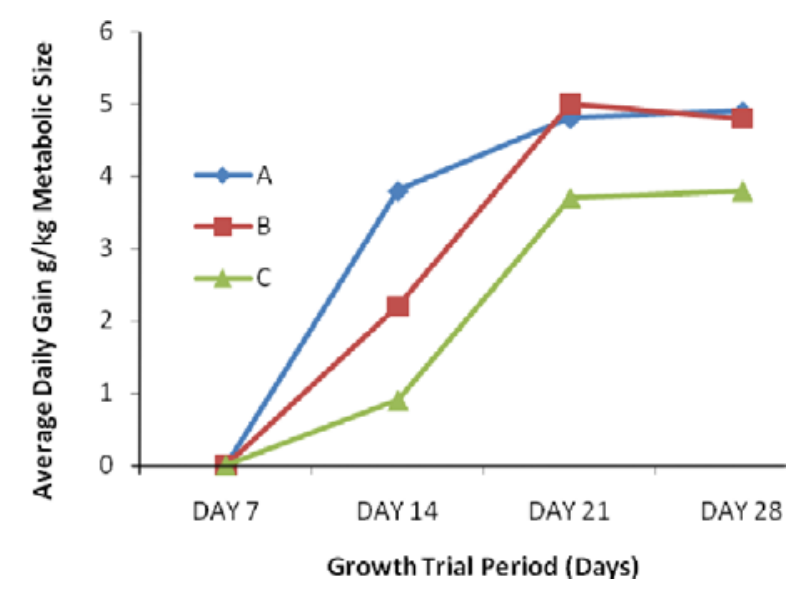

Fig. 1. Variation of average daily body weight gain with growth trial period. A- Flouxymesterone, B- Muruchi Extract, C - Control.

The effect of both the hormone and extract on growth rate has been associated with the excessive excitement observed with animals fed with these substances. This would be explained by the fact that the adrenal corticoids and androgens favour liver catabolic 
activity on amino acids under stress conditions such as the excitement produced by androgens. This catabolic action is further enhanced if there is no adequate supply of readily available energy such as soluble carbohydrates that is needed to reduce the use of amino acids for purposes other than synthetic activities [3]. This situation could also lead to high blood urea as a result of the catabolism of amino acids.

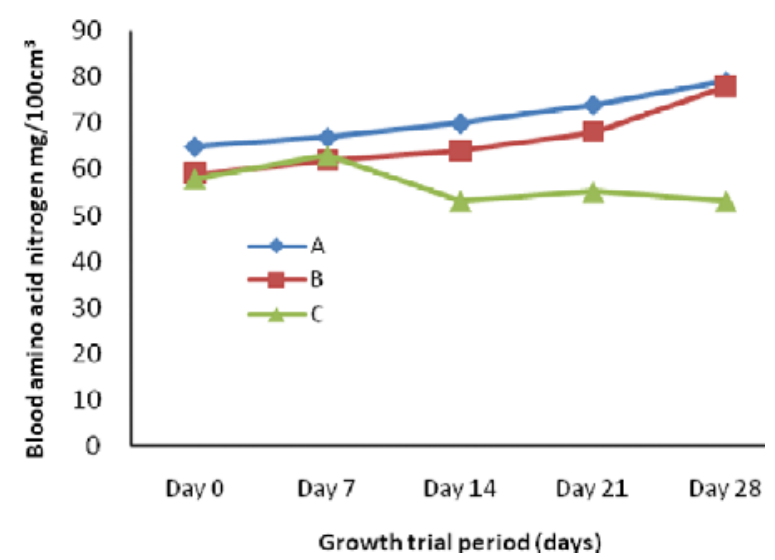

Fig. 2. Variation of blood amino acid nitrogen level with growth trial period. A - Flouxymesterone, B - Muruchi extract, C - Control.

The trends of the blood amino acid nitrogen levels with period of growth trial shown in Fig. 2 indicate anabolic effects in groups fed with hormone and extract. The blood urea nitrogen levels (Fig. 3) also showed upward trend with increasing growth trial period. This might be associated with liver catabolism of amino acids due to excitement brought about by administration of androgens. The results therefore revealed that both the amino

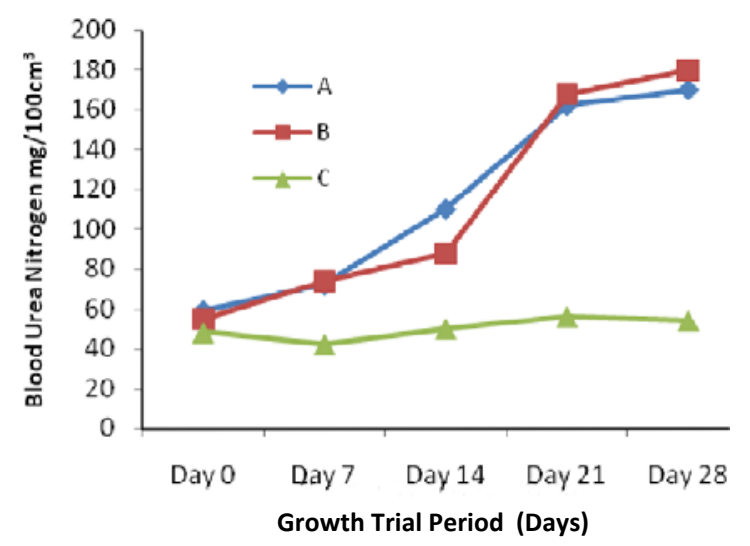

Fig. 3. Variation of blood urea nitrogen level with growth trial period. A - Flouxymesterone, B - Muruchi extract, C - Control. 
acid nitrogen and urea nitrogen levels could be associated with the findings for body weight changes observed during the growth trial. The composition of the animal feed (Harawa) shown in appendix A indicates inadequacy in readily available energy in the ration, which could have effect on the actual anabolic effects.

In comparison with the strongly anabolic standard androgen, fluoxymesterone, the anabolic effect of Muruchi androgens would be considered moderate.

\section{Conclusion}

The growth trial experiment showed that Muruchi extract had anabolic effect since it appreciably increased the growth rate of experimental animals when compared to the standard hormone fluoxymesterone. The variations of blood amino acid and blood urea nitrogen with period of growth also supported the observations in changes in body weights of the experimental animals. The Muruchi extract could therefore be considered to be moderately anabolic and to a large extent supported the local use of Muruchi as an aphrodisiac. It might also find some therapeutic use for muscle and bone nutrition.

In view of the positive anabolic properties of Muruchi, it is strongly recommended that the toxicity of Muruchi should be studied in view of the high rate of its consumption locally.

\section{Acknowledgement}

The authors wish to acknowledge the University of Maiduguri for financial support. We are also indebted to the technical and laboratory staff of the Departments of Chemistry and Veterinary Pathology, University of Maiduguri, for keeping all equipments in proper and good working conditions and for taking care of the experimental animals.

Appendix I. Composition of groundnut tops (Harawa) (Arachis hypogae) [12].

\begin{tabular}{lr}
\hline Nutrient & Composition (\%) \\
\hline Dry matter & 100 \\
Ash & 9.6 \\
Crude fibre & 38.0 \\
Ether extract & 3.6 \\
Nitrogen free extract & 37.7 \\
Protein (N x 6.25) & 11.1 \\
Digestible protein & 6.9 \\
Digestible energy (kJ/kg) & 10500 \\
Metabolic energy (kJ/kg) & 8580 \\
Total digestible nutrients & 56.5 \\
\hline
\end{tabular}

\section{References}

1. A. M. Carl, M. Linda, J. Lan, L. Nathan, J. Ravi, F. John, and B. Shalender, FASEB J. 21: 769.34 (2007). 
2. M. S. Bahrke, C.E. Yesalosk, and J. E. Wright, A Review: Sports Med. 10, 303 (1990). doi:10.2165/00007256-199010050-00003

3. R. G. Van Wayjen, Wien Med. Wochensch, 143 (14-15), 368 (1993).

4. H. G. Williams-Ashman, J. of Cellular and Comparative Physiology 66 (51), 111 (2005).

5. T. P. Coultate, Food: The Chemistry of its components, $5^{\text {th }}$ Revised Ed. (RSC publishing, 2009) pp. 97- 158.

6. L. Egan and E. Sawyer, Chemical Analysis of Food, $7^{\text {th }}$ Edition (Church Hill, Edinburgh 1994) pp 32-37.

7. AMA (American Medical Association), J. Amer. Med. Assoc. 264, 2923 (1990). doi:10.1001/jama.264.22.2923

8. A. I. Vogel, Textbook of Quantitative Chemical Analysis, $6^{\text {th }}$ Revised Edition (Pearson Edu. Ltd. India, 2000) pp 602-607.

9. J. A. Akinniyi, M. Waziri, and H. S. Usman, Study of the Androgen contents of Borassus aethiopum mart, University of Maiduguri Research Report (2000).

10. D. Lorke, Archives of Toxicology 54 (4), 275 (1983). doi:10.1007/BF01234480

11. Software: Analyse-it, General and Clinical Laboratory Analysis (Analyse-it software Ltd. Leeds, England, 2007).

12. E. W. Crampton and L. E. Harris, Applied Animal Nutrition: The use of Feedstuffs in the formulation of Livestock Rations (W.H. Freeman, San Francisco, 1969) p. 753. 